
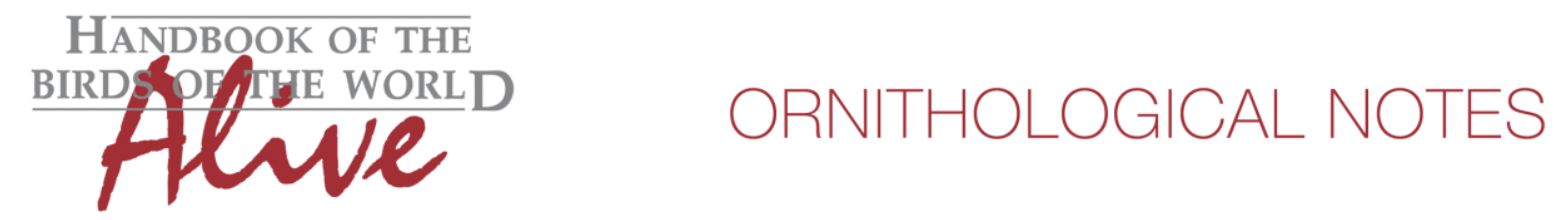

\title{
Notes on the vocalizations of Lesser Elaenia (Elaenia chiriquensis)
}

Peter Boesman

In the following we briefly analyze and compare voice of the three races of Lesser Elaenia (Elaenia chiriquensis). We also try to quantify the extent of any vocal differences using the criteria proposed by Tobias et al. (2010), as a support for taxonomic review.

We have made use of sound recordings available on-line from Xeno Canto (XC) and Macaulay Library (ML).

Members of the genus Elaenia have a dawn song and several day-time 'calls'. Dawn song is usually the most complex vocalization, often quite rhythmic, and< very constant over the entire range of the species (a true suboscine!). Unlike some other Tyrant-flycatchers (e.g. Zimmerius genus), dawn song thus is an excellent indicator for taxonomic decisions.

It is only in recent years that gradually with increasing knowledge more dawn songs of Tyrant flycatchers have been gathered. Obviously, the issue is that birds sing in near-darkness, and identification of the 'singing silhouette' is problematic.

Lesser Elaenia has a dawn-song, a day-time gravelly song, a burry call and a whistled call. Full dawn song of Lesser Elaenia can be described as "tse-rwee...tse-rwee...tse-rwee-gr-grwee" (number of first phrases variable). This rhythmic song can be heard in: Costa Rica, Panama, N and S Venezuela, Guyana, central and SE Brazil and extreme S Ecuador. This covers pretty much the entire range of chiriquensis and albivertex.

brachyptera is known from the foothills of NW Ecuador and SW Colombia. Until recently, only one recording of presumed dawn song was known, a much higher-pitched "tsee...tsee...chee-wee", but this proved to be actually dawn-song of Bran-colored Flycatcher (XC98532), see also http://www.xeno-canto.org/forum/topic/5215. At present there are no known recordings of dawn song for this population.

We can however also look at day-time calls. The 'whistled call' is a mellow "whee" for chiriquensis and albivertex (max. freq. $3500-4100 \mathrm{~Hz}$ ) while it is a much higher-pitched "pee" for brachyptera (max. freq. $5200-5650 \mathrm{~Hz}$ ).

Somewhat similar differences can also be noted for the burry call.

This suggests a significant vocal difference.

There is however one complication: Lesser Elaenia has also been found in foothills of $E$ Ecuador, taxon unknown, but assigned to brachyptera (Moore et al. 2013). The 'whistled call' is like brachyptera (same freq. range and note shape). There is just one presumed dawn song "wit...wit...weedeew".

In a recent paper (Rheindt et al. 2015) (published after the first draft of this note) it was shown that genetically this eastern population is indeed closest to brachyptera, and both populations are far more distant from races chiriquensis and albivertex. 

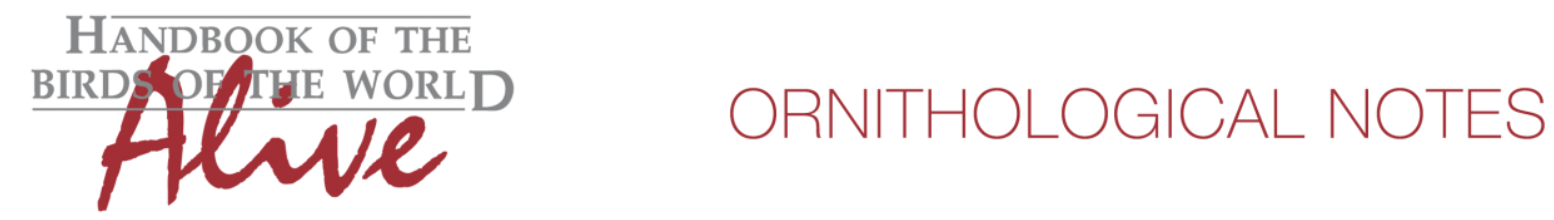

The same paper includes a detailed vocal analysis, in which this single dawn song has been considered representative for brachyptera both east and west of the Andes.

While this is obviously a weak point, there is little more that can be done at this point in time. Obviously, recording the dawn song of the western population is of high priority!

From this vocal analysis, we can quantify vocal differences based on a very different dawn song (much shorter and higher-pitched, score 3) and a markedly higher-pitched day-time call note (score 3), with further differences in voice such as a long rattle call for brachyptera not known for the other races.

If we would apply Tobias criteria, this would lead to a total vocal score of about 6, with the important remark that differences in dawn song of brachyptera are based on just a single recording from a newly discovered population at the other side of the Andes.

This note was finalized on 25th June 2015, and updated on 16th October 2015 using sound recordings available on-line at that moment. We would like to thank in particular the sound recordists who placed their recordings for this species on XC and ML.

\section{References}

Moore, J.V, Krabbe, N. \& Jahn, O. (2013). Bird sounds of Ecuador. John V. Moore Nature recoridngs, San José, Calidornia (MP3-DVD).

Rheindt, F.E., Krabbe, N., Wee, A.K.S. \& Christidis, L. (2015). Cryptic speciation in the Lesser Elaenia Elaenia chiriquensis (Aves: Passeriformes: Tyrannidae). Zootaxa 4032(3): 251-263.

Tobias, J.A., Seddon, N., Spottiswoode, C.N., Pilgrim, J.D., Fishpool, L.D.C. \& Collar, N.J. (2010). Quantitative criteria for species delimitation. Ibis 152(4): 724-746.

\section{Recommended citation}

Boesman, P. (2016). Notes on the vocalizations of Lesser Elaenia (Elaenia chiriquensis). HBW Alive Ornithological Note 132. In: Handbook of the Birds of the World Alive. Lynx Edicions, Barcelona. (retrieved from http://www.hbw.com/node/932055 on 9 August 2016). 